\title{
New generic pricing scheme maintains high prices and risks of shortages
}

\author{
Steven G. Morgan PhD, Nav Persaud MD MSc
}

Cite as: CMAJ 2018 April 9;190:E410-1. doi: 10.1503/cmaj.180197

A S of April 2018, under an agreement between drug manufacturers and public drug plans, Canadian prices of 69 generic drugs will fall by $25 \%-40 \%$ at community pharmacies. ${ }^{1}$ In exchange, governments have promised not to introduce competitive tendering processes for five years, despite having previously committed to putting such pricing policies in place five years ago. ${ }^{2}$ We argue that failure to implement tendering for generic drugs keeps prices unnecessarily high and, paradoxically, increases the risk of drug shortages.

The power of competitive tendering can be seen in virtually every Canadian hospital. In 2017, the Auditor General of Ontario noted that provincial law requires competitive bidding for hospital supply and compared prices for a sample of generic drugs that were used in both the community setting and hospital settings. The Auditor General found hospital prices were $85 \%$ lower than community pharmacy prices and estimated that the Ontario government could have saved $\$ 271$ million annually if the hospital prices had been available to the public drug plan in the community setting. ${ }^{3}$

The noncompetitive pricing scheme to which the governments have recently agreed cannot generate better prices than tendering, for several reasons. Noncompetitive pricing creates secretive competition that requires multiple manufacturers to spend money marketing their product to retailers. As the Competition Bureau noted more than a decade ago, these marketing costs include "professional allowances" and other off-invoice rebates that retailers demand but do not pass on to consumers or drug plans. ${ }^{4}$ Policy-makers cannot know the true cost of making and distributing a drug and therefore cannot know what an appropriate price limit should be.

In contrast, competition under tendering is near perfect, in the economic sense: it is transparent competition that focuses on the final price to the consumer. Each manufacturer bidding in a competitive tender can put in a bid that is very close to the actual cost of making and distributing its drug - plus a sufficient margin to make it worth the effort. Furthermore, firms that win competitive tenders do not have to spend much, if any, money on marketing, because they are given substantial - and often exclusive - market share for the period of the supply contract they have won. This drives down prices.

Some stakeholders suggest that tendering will result in increased generic drug shortages, owing to the fact that

\section{KEY POINTS}

- Manufacturers of generic drugs and Canadian governments have agreed to a noncompetitive generic drug pricing system that will delay competitive generic pricing for at least five years.

- The prices of generic drugs used outside hospitals in Canada will remain several times higher than prices achieved through competitive tendering in Canadian hospitals and in New Zealand.

- Prudently designed tendering processes require manufacturers to ensure the security of supply, which is something that Canada's noncompetitive framework has not achieved.

tendering often results in sole-supply contracts and because prices fall so low that manufacturers no longer have incentive to ensure security of supply. ${ }^{5}$ Both of those claims are false.

Having a single supplier of medicines is a norm in pharmaceutical policy because virtually every patented pharmaceutical is sold by a sole supplier: the patentee. Shortages of patented drugs do occur but are very uncommon. This is because of incentives. Any shortage in supply of a patented drug will represent a substantial loss of profit, because patentees charge prices well above the cost of production. This gives patentees great incentive to manage their supply carefully to prevent or minimize shortages.

A prudent tendering process for generic medicines can mimic such incentives for security of supply of these drugs, even with a sole-source contract, by requiring winning manufacturers to hold certain inventories on hand, to issue minimum notice of any potential shortage, and to pay all additional costs associated with sourcing an alternate supplier in the event of an actual outof-stock occurrence. ${ }^{6}$ Such supply contract terms hold generic manufacturers responsible for security of supply in ways that noncompetitive pricing schemes do not.

Security of supply provisions have been used in the tendering process for New Zealand's universal public drug benefit system for more than 20 years. ${ }^{6}$ According to information from the New Zealand Pharmaceutical Management Agency (PHARMAC), the country gets priority, in the event of a global drug shortage, over other countries that do not have similar commitments from suppliers. ${ }^{7}$ PHARMAC reports that the number of generic firms bidding for these contracts is increasing over time, showing that, 
although manufacturers must factor the costs of the supply commitments into their bids, the system is rewarding to those who win the tenders (Sarah Fitt, PHARMAC [security of supply arrangements under PHARMAC's tendering process], Wellington, NZ: personal communication, 2018).

Tendering is certainly rewarding to New Zealand's public health care system. Using information from the online PHARMAC Schedule and Canada's new generic pricing agreement, we found that 49 of the 69 generic drugs with new, lower prices in Canada had one or more equivalent dosage forms available in both Canada and New Zealand. Weighted according to Canadian usage rates, the new Canadian prices of these drugs are an average of 3.46 times higher than the prices in New Zealand. As just one example, a year's worth of $20 \mathrm{mg}$ atorvastatin would cost $\$ 80$ at the new Canadian prices but only $\$ 8.84$ in New Zealand. Such major differences in price exist despite the fact that no manufacturers are responsible for ensuring a stable supply in Canada, yet each manufacturer is responsible for doing so in New Zealand.

Given the clear benefit of competitive tendering, why do governments remain reluctant to implement this process? Stakeholder opposition is surely one reason. Hundreds of millions of dollars in profit are at stake for retail pharmacies and pharmaceutical manufacturers. Another reason for limited progress is division of responsibility. In Canada's hospital settings, governments are clearly responsible for ensuring a secure supply of medicines at competitive prices. Hospitals have run tendering processes for decades with few problems, sometimes even opting to run multisource supply contracts to mitigate risks. Nevertheless, governments must accept responsibility if things go wrong in the hospital sector. Governments in Canada are not, yet, in such a position of responsibility for prescription drugs outside of hospitals. Politicians may therefore prefer the relative simplicity of noncompetitive price agreements that come with fewer political risks, even if the policy outcomes are inferior to government-managed tendering processes.

For the purpose of both securing supply of medicines that Canadians need and generating savings for governments and citizens, policy-makers should get on with the task of implementing long-promised tendering processes for generic drugs. The noncompetitive pricing agreements they have been striking with industry for years now come without the benefit of either guaranteed supply or competitive prices. This puts Canadians at avoidable risk and our health system under unnecessary financial strain.

\section{References}

1. Pan-Canadian Pharmaceutical Alliance. A joint statement from the pan-Canadian Pharmaceutical Alliance and the Canadian Generic Pharmaceutical Association [press release]. 2018 Jan. 29. Toronto: CNW Group; 2018.

2. From innovation to action: the first report of the Health Care Innovation Working Group. Ottawa: Council of the Federation Secretariat; 2012.

3. 2017 Annual report volume 1. Toronto: Office of the Auditor General of Ontario. Toronto: 2017.

4. Generic Drug Sector Study. Ottawa: Competition Bureau Canada; 2007.

5. Perreaux L, Van Praet N. Industry warns against Quebec's drug plan, citing potential shortages. Globe and Mail [Toronto]; 2017 June 28.

6. Morgan S, Daw JR, Thomson PA. International best practices for negotiating "reimbursement contracts" with price rebates from pharmaceutical companies. Health Aff (Millwood) 2013;32:771-7.

7. Managing medicine supply. Wellington (NZ): PHARMAC; 2016. Available: www pharmac.govt.nz/assets/factsheet-07-managing-medicine-supply.pdf (accessed 2018 Feb. 12).
Competing interests: Nav Persaud reports research funding from the Canadian Institutes of Health Research and the Ontario Strategy for Patient-Oriented Research (SPOR) Support Unit, outside of the submitted work. No other competing interests were declared.

This article was solicited and has not been peer reviewed.

Affiliations: School of Population and Public Health (Morgan), University of British Columbia, Vancouver, BC; Department of Family and Community Medicine (Persaud), the University of Toronto, Toronto, Ont.
Contributors: Steven Morgan conceived of the article and obtained generic drug pricing data from Canada and New Zealand. Both authors drafted the manuscript, revised it critically for important intellectual content, gave final approval of the version to be published and agreed to be accountable for all aspects of the work.

Disclaimer: Nav Persaud is an associate editor for CMAJ and was not involved in the editorial decision-making process for this article.

Correspondence to: Steven Morgan, steve.morgan@ubc.ca 